\title{
Anaesthetic implications of calcium channel blockers
}

\section{CONTENTS}

Physiology - calcium/calcium channel blockers Uses of calcium channel blockers

Traditional

Angina pectoris

Arrhythmias

Hypertension

Newer and investigational

Cardiac

- Hypertrophic cardiomyopathy

- Cold cardioplegia

- Pulmonary hypertension

Actions on platelets

Asthma

Obstetrics

- Premature labor

- Pre-eclampsia

Achalasia and oesophageal spasm

Increased intraocular pressure therapy

Protective effect on kidney after radiocontrast

Cerebral vasospasm

Induced hypotensive anaesthesia

Drug interactions with calcium channel blockers

With anaesthetic agents

Inhalation agents

- Effect on haemodynamics

- Effect on MAC

Neuromuscular blockers

Effects on epinephrine-induced arrhythmias

With other drugs

Digoxin

Beta adrenergic blockers

Quinidine

Theophylline

Dantrolene

Pathophysiological alterations (other than cardio vascular) with anaesthetic implications

Decrease in lower oesophageal sphincter tone

Effects on intracranial hypertension

Asthma

Muscular dystrophy

Hypoxic pulmonary vasoconstriction

Malignant hyperthermia

Inhibition of platelet aggregation

Hyperkalemia

Summary
Leonard C. Jenkins BA MD CM FRCPC

Peter J. Scoates B SC MD FRCPC
The object of this review is to emphasize the anaesthetic implications of calcium channel blockers for the practising anaesthetist. These drugs have played an expanding role in therapeutics since their introduction and thus anaesthetists can expect to see increasing numbers of patients presenting for anaesthesia who are being treated with calcium channel blockers. Other reviews have emphasized the basic pharmacology of calcium channel blockers. ${ }^{1-7}$

Physiology - calcium/calcium channel blockers Calcium plays an important role in many physiological processes, such as blood coagulation, enzyme systems, muscle contraction, bone metabolism, synaptic transmission, and cell membrane excitability. Especially important is the role of calcium in myocardial contractility and conduction as well as in vascular smooth muscle reactivity. ${ }^{7}$ Thus, it can be anticipated that any drug interfering with the action of calcium could have widespread effects.

In order to understand the importance of calcium in cellular excitation, it is necessary to review some membrane physiology. Cell membranes are primarily phospholipids arranged in a bilayer. Interspersed throughout are macromolecular proteins and glycoproteins traversing the membrane, forming channels. These channels are relatively specific to certain ions. Recently, channels which regulate

From the Department of Anaesthesia, Faculty of Medicine, University of British Columbia, Vancouver General Hospital and Royal Columbian Hospital, Vancouver, British Columbia.

Address correspondence to: Dr. Leonard C. Jenkins, Department of Anaesthesia, University of British Columbia, Room 3200, 910 West 10th Avenue, Vancouver, British Columbia V5Z 4E3. 
flow of sodium and calcium have been identified. The sodium channels are also known as fast channels because influx of sodium via these channels is responsible for the rapid (phase 0) upstroke of the action potential seen in the myocardial cell. The calcium channels are known as slow channels because when fast channels are blocked, as with lidocaine, the resulting action potential has a slowly rising and falling pattern as seen in the normal SA node or AV node action potential.

Calcium fluxes play an important role in altering the membrane potential during cellular excitation in most myocardial cells. Sodium influx produces the phase 0 of the action potential and calcium influx during phase 1 and 2 of the action potential contributes to the formation of the plateau. ${ }^{2,6}$ However, in the SA node and AV node of the heart, calcium is the important ion responsible for phase 0 depolarization, not sodium. Under abnormal conditions such as hypoxia and ischaemia, ventricular cells may also become dependent on calcium for production of phase 0 of the action potential. ${ }^{2}$

The flow of ions through the membrane channels have been shown to be regulated by a number of gates. This is most clearly demonstrated for the sodium channels but is felt to be similar for calcium channels. ${ }^{4}$ The external surface of the membrane has gates which open and close in response to voltage changes in the membrane (voltage dependent gates). The internal surface has gates which depend on phosphorylation of ATP to control ion flows (phosphorylation dependent gate). For example, histamine or beta-adrenergic drugs may induce the formation of cyclic AMP thus modifying channel proteins and altering calcium influx.?

Calcium also plays a major role in bringing about excitation-contraction coupling. In striated and cardiac muscle, calcium ions in the cell inhibit the binding of troponin and tropomyosin and thus bring

TABLE I Drugs that interfere with calcium actions

Ions: Various di- and trivalent cations

Calcium entry blockers: verapamil, nifedipine, diltiazem, lidoflazine tiapamil and others Papavarine

Procaine, procainamide

Phenytoin

Diazoxide, nitroprusside, nitroglycerine Inhalational anaesthetics: halothane, enflurane and isoflurane

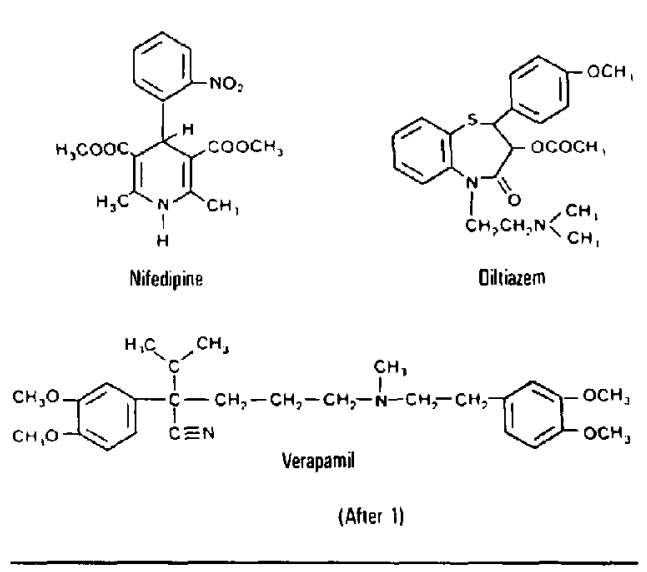

FIGURE

about contraction. In smooth muscle, calmodulin, rather than troponin acts as the receptor protein. Rapid reduction of calcium ion concentration in the sarcoplasma must occur for relaxation to take place. In skeletal muscle the calcium needed for excitation-contraction is stored in the sarcoplasmic reticulum and energy dependent processes bring about its re-uptake after release. Cardiac muscle contains relatively small amounts of stored calcium and vascular smooth muscle even less. These latter tissues depend to a greater extent on transmembrane influx of calcium for contraction to occur. It appears that the calcium entering the cell during the plateau phase plays an important role in inducing calcium release from the sarcoplasmic reticulum, thus bringing about contraction. $1,2,4,7,8$

The drugs currently used as specific calcium channel blockers are verapamil, nifedipine and diltiazem. These drugs are but a few of the myriad drugs that possess calcium blocking activity (Table I).

A review of the structure of these drugs shows that they vary greatly. The figure depicts the structures of verapamil, nifedipine and diltiazem. ${ }^{\prime}$ This variability implies that there is no one receptor that mediates the effects of the calcium channel blockers.

Calcium channel blockers function by altering calcium uptake across the cellular membrane and also by affecting intracellular uptake and release mechanism. ${ }^{2,8}$ Verapamil, which exists in a D \& L isomer form in commercial preparations, acts pri- 
TABLE II Summary of clinical effects of calcium channel blockers on the curdiovascular system (in vivo)

\begin{tabular}{lllll}
\hline & $\begin{array}{l}\text { Heart rate and AV } \\
\text { conduction }\end{array}$ & $\begin{array}{l}\text { Cardiac } \\
\text { depression }\end{array}$ & & \multicolumn{2}{l}{ Vasodilation } \\
\cline { 2 - 5 } & systemic & coronary \\
\hline Verpamil & +++ & ++ & ++ & ++ \\
Nifedipine & 0 & 0 & +++ & +++ \\
Diltiazem & + & + & ++ & +++ \\
\hline
\end{tabular}

AV - atrioventricular

marily at the inner phosphorylation dependent gate of the membrane. It has also been shown that the D isomer of verapamil acts almost exclusively as a fast channel blocker and is almost devoid of slow channel inhibition. Diltiazem also has some fast channel inhibition. Nifedipine is believed to act primarily at the voltage dependent (outer) gate of the calcium channel ${ }^{2,3,7}$ Diltiazem appears to act at the inner phosphorylation dependent gate, like verapamil. $^{8}$

Most cardiovascular effects of calcium channel blockers can be explained on the basis of selective inhibition of transmembrane influx of $\mathrm{Ca}^{++}$. Inhibition of $\mathrm{Ca}^{++}$dependent membrane excitation accounts for the depressive effect of calcium channel blockers on sinus automaticity and atrioventricular conductivity. Interference with the excitation-contraction coupling process is the reason for their negative inotropic effect. The effects of calcium channel blockers on the vascular smooth muscle may result from either inhibition of excitation contraction coupling or from suppression of $\mathrm{Ca}^{++}$ dependent smooth muscle spike activity.

Table II is a summary of the clinical effects of calcium channel blockers on the cardiovascular system. Verapamil and nifedipine seem to be at ends of the spectrum of clinical activity, with diltiazem in the middle. All calcium channel blockers have a negative inotropic and chronotropic effect in vitro with nifedipine having the greatest effect. ${ }^{6}$ Alternately, in the intact organism, there are reflex responses that offset these negative effects. The potent vasodilating effect of nifedipine causes a decrease in afterload which results in a sympathetic stimulation of the heart via the baroreceptors. Thus, in vivo, nifedipine has negligible effect on myocardial depression, sinus node activity and AV conduction. Alternatively, verapamil has its greatest effect on the sinus node activity, thus making it very useful for terminating supraventricular arrhythmias, whereas nifedipine has no activity in this regard.

It is interesting that both nifedipine and isoflurane have little (but are not devoid of) influence on contractility and conduction, but markedly reduce systemic vascular resistance. Patients exposed to both drugs may be expected to exhibit additive effects, which may be significant, on systemic vascular resistance and blood pressure, but little disturbance of myocardial contractility or conduction. However, verapamil, in a dose which causes the same reduction in arterial pressure as nifedipine, significantly impairs cardiac conduction and contractility. ${ }^{2}$ Similarly, the blood pressure decrease which accompanies halothane anaesthesia is principally due to reduced myocardial contractility - and halothane appears to depress conduction more than isoflurane. ${ }^{2}$ Thus, a patient exposed to verapamil and halothane may be expected to exhibit additive effects on contractitlity and AV nodal conduction.

\section{Uses of calcium channel blockers}

\section{Traditional}

Initially, calcium channel blockers were introduced for the treatment of angina, arrhythmias and hypertension.

The benefits for the patient with angina are twofold. First, the calcium channel blockers act as coronary vasodilators and increase blood supply to the myocardium. This is especially relevant in the treatment of patients with Prinzmetal's angina. Secondly, peripheral vasodilation tends to decrease afterload and therefore reduce the work of the heart and reduce myocardial oxygen consumption. Decreased myocardial contractility also reduces the oxygen consumption. 2,4

In the treatment of arrhythmias, verapamil and to 
a lesser extent diltiazem have been found to be effective in terminating supraventricular arrhythmias. Verapamil is now considered the agent of choice in terminating acute episodes of paroxysmal supraventricular tachycardia in adults and children. The effect is produced as a result of slowing of conduction through the AV node and/or prolonging refractoriness. ${ }^{2}$ Nifedipine, because it has negligible effects on the SA node or AV node is not useful for treatment of supraventricular arrhythmias. Ventricular arrhythmias are not particularly responsive to calcium channel blockers. ${ }^{2}$

Hypertension has been successfully treated with the calcium channel blockers. Decrease in systemic vascular resistance produced by nifedipine can be used to manage hypertension. ${ }^{2}$

\section{Newer and investigational uses}

\section{Cardiac}

Recent studies have successfully demonstrated the use of nifedipine in hypertrophic cardiomyopathy ${ }^{9}$ and as an adjunct to cold cardioplegia. ${ }^{10}$ Nifedipine has been reported as a beneficial inhibitor of hypoxic pulmonary vasoconstriction ${ }^{11}$ in pulmonary hypertension and in patients with chronic obstructive puimonary disease. ${ }^{12}$

\section{Actions on platelets}

Both nifedipine and verapamil have been shown to inhibit aggregation of platelets caused in vitro by collagen, the second phase of ADP induced aggregation and aggregation caused by ionophore A23187 13 (see also discussion on inhibition of platelet aggegation).

\section{Asthma}

Verapamil and nifedipine have been studied for potential benefits in the treatment of both intrinsic asthma and exercise induced asthma. ${ }^{14.15}$ Verapamil has been shown to inhibit post-exercise induced bronchospasm in susceptible persons. ${ }^{15}$

\section{Obstetrics}

Merin $^{1}$ has suggested that the smooth muscle dilating effects may be therapeutic for premature labour in obstetrics and also therapeutic for preeclamptic toxemia of pregnancy, by virtue of the vasodilating effects. Investigational clinical trials are being contemplated.
Achalasia and oesophageal spasm ${ }^{16-18}$

Studies in which patients received infusions of verapamil ${ }^{16}$ and nifedipine ${ }^{17,18}$ resulted in a statistically significant decrease in resting lower oesophageal pressure in both normal subjects and patients with achalasia. The studies suggested that verapamil may have a potential use as a drug therapy in treating the clinical symptoms of achalasia and diffuse esophageal spasm.

Increased intraocular pressure therapy ${ }^{19}$

It has been shown clinically that calcium channel blockers are capable of significantly decreasing raised intraocular pressure.

Protective effect on kidney after radiocontrast

Studies have shown a lack of rise of plasma creatinine in patients treated before coronary angiograms with nifedipine compared to those without pretreatment, ${ }^{20}$ thus indicating a possible future role in renal protection.

\section{Cerebral vasospasm ${ }^{2}$}

Calcium channel blockers are potent cerebral arterial dilators. ${ }^{2}$ Cerebral arterial spasm induced by a variety of techniques in laboratory animals is blocked by nifedipine and verapamil. However, there are no large, well-designed investigations in humans showing the efficacy of calcium channel blockers in intracerebral arterial spasm.

\section{Induced hypotensive anaesthesia}

Verapamil has been given as single $0.07 \mathrm{mg} \cdot \mathrm{kg}^{-1}$ boluses to electively induce hypotension in patients undergoing neuroleptanaesthesia. Mean blood pressure decreased from 108 to 84 ( $p<$ 0.001 ) without significant change in heart rate or pulmonary artery pressure. These effects were reversed by $15 \mathrm{mg} \cdot \mathrm{kg}^{-1}$ of calcium gluconate. For a prolonged effect, an infusion of verapamil would be necessary. ${ }^{2}$

\section{Drug interactions with calcium channel blockers}

It is apparent that calcium channel blockers may interact with anaesthetic agents and also with other drugs which are commonly encountered in surgical patients.

\section{With anaesthetic agents}

INHALATION AGENTS

Haemodynamic effects. Only one human study has 
been reported demonstrating the interaction of halothane anaesthesia and intravenous verapamil $0.15 \mathrm{mg} \cdot \mathrm{kg}^{-1}$ given over ten minutes. ${ }^{21}$ This study investigated eight patients scheduled for coronary artery bypass surgery. All patients had normal left ventricular function at rest and were being treated with long-term beta-adrenergic blockers. Halothane produced a marked reduction in mean arterial pressure, cardiac index, and left ventricular contractility as documented by a decrease in left ventricular peak positive $\mathrm{dP} / \mathrm{dT}$. Addition of verapamil caused further depression ( 16 per cent) of left ventricular peak positive dP/dT accompanied by a small increase $(3 \mathrm{mmHg})$ in left ventricular enddiastolic pressure. The combined negative inotropic properties of halothane and verapamil did not produce any overt untoward effects even in the presence of chronic low-dose beta-blocker therapy. The predominant haemodynamic effect of verapamil was systemic vasodilation resulting in a further reduction in MAP (12 per cent) while heart rate remained unaffected. The $P R$ interval remained unchanged throughout the study. The authors pointed out that, despite the reduced myocardial oxygen demand, caution must be exercised in dose selection of each drug to avoid regional myocardial ischaemia due to the combined hypotensive effects of halothane and verapamil. This study is applicable only in patients with normal left ventricular function at rest. Studies in animals $\mathrm{s}^{22-24}$ also show similar changes to those reported in man.

In essence, when dealing with patients who are being treated with yerapamil, one should be cautious in using this agent with halothane and/or further verapamil as significant myocardial depression may result. This may be especially impotant in patients with pre-existing myocardial impairment.

No studies of interactions of nifedipine or diltiazem with inhalational agents have been reported and only one study in animals ${ }^{25}$ demonstrated the effects of verapamil with other inhalational agents (enflurane and isoflurane). In this study, there was a lower blood pressure, more myocardial depression and more conduction abnormalities with enflurane and verapamil than with either halothane or isoflurane.

Effects on MAC. Only one study has shown the effects of calcium channel blockers in depth of anaesthesia ${ }^{26}$ as reflected by the manner in which verapamil alters MAC for halothane in dogs. MAC was reduced from 0.97 to 0.72 per cent. Knowledge that verapamil treatment increased the depth of anaesthesia, possibly on the basis of fast channel blockade, may require adjustment of the dose of anaesthetic agent. However, no human data are available to date.

\section{Neuromuscular blockers}

Currently there are no published controlled studies in man evaluating the interactions of neuromuscular blocking agents and the calcium channel blockers. Considerable animal data have been collected and, although showing some species variation, they strongly suggest an important effect at the neuromuscular junction.

Studies of the effects of calcium channel blockers alone on the neuromuscular junction have revealed that in most species there is a progressive doserelated reduction in twitch height with the administration of verapamil or nifedipine. ${ }^{23,24,27-30}$ Diltiazem has been shown to augment indirect twitch tension when administered to dogs. ${ }^{8}$

In animals, effects of both depolarizing muscle relaxants $^{29,30}$ and nondepolarizing muscle relaxants are augmented by verapamil. ${ }^{27,29-31}$ However, again, human evidence is lacking. The reversal of the combined muscle relaxant/calcium channel blocker paralysis did not seem to be any different to that without the calcium channel blocker. ${ }^{27,31}$

Although no human research has been done, two case reports have recently appeared in the literature that indicate problems when calcium channel blockers have been used. ${ }^{32,33}$

A patient with Duchenne's muscular dystrophy ${ }^{32}$ presented with atrial flutter. Following administration of $6.0 \mathrm{mg}$ verapamil, he became cyanotic and lost consciousness. He was ventilated by mask and intubated.

Subsequent cardioversion reverted his rhythm to normal sinus rhythm. However, despite haemodynamic stability and clear sensorium he was not able to be extubated because of respiratory insufficiency. Verapamil appeared to have triggered the precipitous apnoea. The authors suggest that the margin of safety of the neuramuscular junction must be impaired before the neuromuscular blocking effects of verapamil become clinically apparent. Van Poorten ${ }^{33}$ reported a case of prolonged 
paralysis after vecuronium in a patient being treated with verapamil. The patient was a 66 year old with renal failure controlled with regular dialysis. She developed intra-abdominal sepsis and also episodes of intermittent supraventricular tachycardia necessitating treatment with $5 \mathrm{mg}$ of verapamil IV three times daily. She was booked for exploratory laparotomy, no antibiotics were given three days prior to surgery and she was dialyzed the day prior to surgery. Anaesthesia was induced with $200 \mathrm{mg}$ thiopentone and maintained with 66 per cent nitrous oxide in oxygen. Tracheal intubation was achieved with $8 \mathrm{mg}$ vecuronium and fentanyl was administered as required. Ten minutes after induction a further $2 \mathrm{mg}$ of vecuronium was given based on a single twitch response to two per cent of control value. No further vecuronium was needed for another 90 minutes when a further $1 \mathrm{mg}$ was given. The operation ended 50 minutes after the last dose of vecuronium; single twich response was 20 per cent of control value and administration of $3 \mathrm{mg}$ neostigmine and $1 \mathrm{mg}$ atropine returned single twitch response to only 60 per cent of control. A total of $3 \mathrm{mg}$ more of neostigmine was given over the next 90 minutes before the patient was sufficiently recovered to permit extubation. Compared to their previous experience with renal failure patients and vecuronium administration, the authors suggest that this represented both a prolonged dosing interval and prolonged recovery. The authors stated that, in most renal failure patients, a comparable dose required top ups at 20-30-minute intervals and could always be reversed with neostigmine.

They concluded that the verapamil caused the prolongation of the block. They did not consider other causative possibilities such as myasthenic syndrome.

Much speculation has been generated to explain the causes of the prolongation of neuromuscular block effects. Presynaptic alterations could be responsible by reducing calcium conduction, altering intracellular presynaptic calcium pools, cyclic AMP levels, or inhibiting membrane calcium pump mechanisms. All of these effects could lead to an interference of acetylcholine mobilization or release. It has also been postulated that these effects could be due to a local anaesthetic action of verapamil on nerve conduction as a result of blockade of sodium channels. Verapamil has shown to be 1.6 times as potent as procaine ${ }^{2}$ in this regard. Overall, the animal data and the human case reports strongly suggest that there is an augmentation of both depolarizing and nondepolarizing neuromuscular blockade when calcium anatagonists are concurrently administered. The anaesthetist should be aware of this potential problem and should carefully monitor the neuromuscular junction, titrating drugs to the desired effect.

\section{Effects on epinephrine induced arrhythmias ${ }^{22}$}

The antiarrhythmic effects of verapamil were studied during 1.1 MAC halothane anaesthesia in dogs, in which the epinephrine arrhythmogenic dose was determined with and without the addition of $0.2 \mathrm{mg} \cdot \mathrm{kg}^{-1}$ of verapamil. Verapamil elevated the dose of epinephrine required to produce ventricular arrhythmia. Verapamil was also shown to be effective in terminating episodes of ventricular tachycardia induced by epinephrine infusion but not regular ventricular tachycardia. The relevance of these data to humans is yet to be determined.

\section{INTERACTION WITH OTHER DRUGS}

Digoxin $^{34}$ - Verapamil reduces the total body clearance of digoxin by 35 per cent due to impairment of its elimination. This results in an increase in plasma concentrations by $60-80$ per cent. Verapamil does not alter the positive inotropic effect of digoxin on the heart as shown by measurements of systolic time intervals. ${ }^{34}$ This is clinically important, as addition of verapamil to steady-state digoxin therapy could precipitate digitalis toxicity.

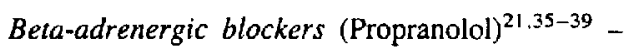
Considerable attention has been placed on the possible interactions of calcium channel blockers and beta-adrenergic blockers for several reasons. Calcium channel blockers, and especially nifedipine, depend on reflex sympathetic stimulation to ameliorate the direct depressant effects that they have on the myocardium. Thus, when a betaadrenergic blocker is added, it will unmask the direct effects of the calcium channel blocker. ${ }^{37}$ Both beta-adrenergic blockers and verapamil and diltiazem slow conduction through the $\mathrm{AV}$ node and have direct myocardial depressant effects.

There are numerous case reports that show significant problems when verapamil and beta- 
adrenergic blockers are used together. ${ }^{35}$ In most instances, verapamil was used to treat paroxysmal supraventricular tachycardia, atrial fibrillation or flutter. Adverse reactions varied from hypotension, AV block and bradycardia to asystole and cardiogenic shock. Most, but not all patients, had underlying cardiac disease. ${ }^{36-39}$ Thus, current guidelines ${ }^{35}$ for use of intravenous verapamil in the presence of, or coincidentally with, beta-blockers are: (a) the patient should have ECG monitoring; (b) the administration of calcium channel blockers should be separated by six hours from prior beta-adrenergic administration in patients with underlying heart disease; (c) the combination of calcium channel blockers and beta-adrenergic blockers should not be administered to patients with AV node disease, congestive heart failure or cardiomyopathy.

One study does report negligible ${ }^{36}$ myocardial depressant effects and no change in heart rate when patients receiving chronic propranolol therapy were treated with up to $0.1 \mathrm{mg} \cdot \mathrm{kg}^{-1}$ of verapamil intravenously during heart catheterization. All patients studied had normal left ventricular function.

Other studies ${ }^{35,39}$ have demonstrated the safety of oral verapamil concomitantly used with betaadrenergic blockers in the treatment of angina pectoris. Once again, all these patients had normal left ventricular function.

Finally, if an adverse interaction does occur after administration of concomitant IV verapamil and oral or IV beta-adrenergic blockers, treatment should consist of atropine, isoproterenol, calcium and/or temporary pacing when necessary. ${ }^{35}$ Further studies are needed to understand the exact mechanism of this drug interaction.

Thus, it would seem prudent to avoid the combinations of verapamil or diltiazem with betablockers if at all possible, especially in patients with underlying cardiac disease. Although verapamil has been given safely to patients receiving beta blockers, $21,37,38,39$ all these studies have been done on patients with normal left ventricular function, so this must be borne in mind if one considers using the combination.

Quinidine $e^{40}$ - A nifedipine-quinidine interaction was reported in a 51-year-old male. He had an acute anteroseptal myocardial infarction, developed congestive heart failure, with an ejection fraction of 20 per cent and was treated with quinidine for ventricu- lar ectopy. After achieving control of his arthythmias, and with steady quinidine blood levels, he developed angina and, therefore, nifedipine $10 \mathrm{mg}$ three times a day was added. The ventricular ectopy recurred and quinidine levels showed a significant decline. The dose of quinidine was increased to control the ectopy. When nifedipine was subsequently discontinued, quinidine levels rose into the toxic range.

The authors speculate that it was most likely nifedipine, through dilatation of the peripheral vasculature and possible augmentation of cardiac output (by decreasing afterload), that has increased the volume of distribution of quinidine. In treating patients who are receiving quinidine, it would appear possible that introduction of nifedipine may lower quinidine levels and decrease effectiveness of the drug.

Theophylline $e^{41,42}-$ A case history ${ }^{41}$ was reported of a 76-year-old patient with chronic obstructive pulmonary disease who was treated with sustained release theophylline and who developed paroxysmal supraventricular tachycardia. She was treated with verapamil $80 \mathrm{mg} q 8 \mathrm{~h}$. There was an initial good response and then a gradually increasing heart rate and increasing nausea. The theophylline level was $27.9 \mu \mathrm{g} \cdot \mathrm{ml}^{-1}$, up from $14.5 \mu \mathrm{g} \cdot \mathrm{ml}^{-1}$ at the time of administration, prior to verapamil.

The authors felt that the most likely cause of the problem was competitive hepatic metabolism. Verapamil and theophylline both undergo extensive first pass metabolism and have the $\mathrm{N}$-demethylation process in common.

The possibility of elevated concentrations of theophylline must be considered when verapamil or nifedipine ${ }^{42}$ therapy is used in a patient being treated with theophylline.

Dantrolene - A recent report concerns swine (nonMH susceptibles) ${ }^{43}$ anaesthetized with chloralose and then started on verapamil $0.1 \mathrm{mg} \cdot \mathrm{kg}^{-1}$ bolus followed by an infusion of $0.005 \mathrm{mg} \cdot \mathrm{kg}^{-1} \cdot \mathrm{hr}^{-1}$. After one hour, dantrolene was given in boluses of $1.0,3.3$ and $5.6 \mathrm{mg} \cdot \mathrm{kg}^{-1}$. All animals showed a profound decrease in cardiac output, and mean arterial pressure, and increase in central venous pressure, pulmonary artery pressure and pulmonary capillary wedge pressures. All animals died with complete AV block followed by cardiac arrest. The 
authors suggest that the mechanism of action was due to the additive effects of verapamil blocking the calcium influx across slow channels in cardiac and vascular smooth muscle cells and the dantrolene blocking the calcium release from the sarcoplasmic reticulum that were responsible for the deaths. The authors admit that, although data from a porcine model cannot be extrapolated to humans, they felt that further studies were indicated to help evaluate a possible fatal drug interaction before verapamil and dantrolene are used concomitantly in a clinical setting. ${ }^{43}$

Another study ${ }^{44}$ investigated cardiovascular changes in dogs anaesthetized with chloraloseurethane when varying doses of dantrolene and verapamil were used. Although dantrolene was felt to augment the myocardial depression seen with verapamil and also prolong the $P R$ and $A V$ intervals, it was not to the same dramatic extent seen in the previous case reported. However, the authors felt that the combination of the drugs offered no advantage that justified their concomitant use.

\section{Pathophysiological alterations (other than cardiovascular) with anaesthetic implications}

Decrease in lower oesophageal sphincter tone ${ }^{16-18}$ Several studies have demonstrated that calcium channel blockers can reduce lower oesophageal sphincter tone, in both normal subjects and in patients with achalasia or oesophageal spasm.

Verapamil $^{16}$ given in a dose of $0.15 \mathrm{mg} \cdot \mathrm{kg}^{-1}$ intravenously over a two-minute period can decrease lower oesophageal sphincter tone by 30 per cent, in both normal and symptomatic patients. The duration of their effect was 25 minutes. The authors did not comment on the possible complications of potential regurgitation predilection.

In another study, ${ }^{17}$ nifedipine was given as a sublingual dose 10-20 mg. Lower oesophageal sphincter tone was also reduced by 30 per cent with the effect retuming to baseline by one hour, in patients with achalasia. Nifedipine was also studied as to the effects on gastric emptying time and lower oesophageal sphincter pressure (LESP) in normal humans. ${ }^{18}$ The LESP fell from 17.6 to $7.7 \mathrm{mmHg}$ in these normals. There was no significant influence on the rate of gastric emptying.

This significant reduction in LESP by calcium channel blockers may have important anaesthetic implications in that the risk of regurgitation occurring during induction of anaesthesia and during mask ventilation techniques is increased in patients on these drugs, due to the drugs' ability to lower the amount of pressure necessary to open the lower oesophageal sphincter. Fortunately, there appears to be no effect on gastric emptying time.

\section{Effects on intracranial hypertension ${ }^{45}$}

Calcium channel blockers ${ }^{45,46}$ are believed to be potent cerebral vasodilators, as well as antihypertensives. There is thus the potential of contributing to an increase in intracranial pressure similar to that which is known to occur with nitroglycerine ${ }^{47}$ and nitroprusside. ${ }^{48}$

Studies of the effects of nifedipine on intracranial pressure (ICP) in cats ${ }^{46}$ both with normal and increased ICP, demonstrated a significant increase in ICP in both groups, but it was consistently larger in the group of cats already compromised. There was an associated critical reduction in cerebral perfusion pressure.

Verapamil has been studied in ten hypertensive patients $^{45}$ with supratentorial mass lesions, under general anaesthesia. Significant increases in ICP were seen (18 to $27 \mathrm{mmHg}$ versus a reduction from 18 to $11 \mathrm{mmHg}$ in control patients), following $5.0 \mathrm{mg}$ of verapamil intravenously. Cerebral perfusion pressure was also significantly reduced in the verapamil versus the control group despite similar reductions in mean arterial pressure (MAP). The increases in ICP were readily reversed with hyperventilation and intravenous lidocaine $\left(1.5 \mathrm{mg} \cdot \mathrm{kg}^{-1}\right)$. The authors concluded that calcium channel blockers should be avoided in patients with compromised intracranial compliance unless ICP is being monitored and proper therapy for intracranial hypertension can be readily instituted.

\section{Asthma}

Because calcium channel blockers play a role in relaxation of smooth muscle, they have been studied in relation to clinical use in asthma. Nifedipine, $20 \mathrm{mg}$ orally ${ }^{14}$ did not produce any effect on the $\mathrm{FEV}_{1}$ of patients with intrinsic asthma, however, subsequent inhalation of terbutaline produced a significantly greater bronchodilatory effect compared to a group that received placebo instead of nifedipine. The study showed that nifedipine potentiated beta adrenoceptor mediated broncho- 
dilatation. This is of importance when treating patients with simultaneous asthma and hypertension or angina pectoris.

Other studies ${ }^{15,49}$ have shown the lack of effect of nifedipine or verapamil on baseline airway resistance. Verapamil, however, has been shown to have a protective effect on exercise induced asthma equal to that of sodium cromoglycate. ${ }^{15}$ This is postulated to be in part related to inhibition of mediator release (histamine, prostaglandins) from mast cells.

From these studies, it is useful to know that calcium channel blockers, unlike beta-adrenergic blockers, will not have a detrimental effect on bronchial smooth muscle in asthmatic patients requiring these agents for the treatment of hypertension, angina or dysrhythmias. It could be anticipated that there may, indeed, be some potentiation

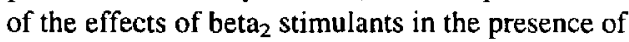
calcium channel blockers.

\section{Muscular dystrophy}

The patient with Duchenne's muscular dystrophy ${ }^{32}$ referred to previously received verapamil and developed respiratory arrest. The current consensus is that calcium channel blockers do not produce any detrimental effect on the neuromuscular function of humans, unless there is some pre-existing compromise. The implication is, though, to titrate calcium channel blockers very cautiously in patients with neuromuscular problems, or avoid altogether, by choosing alternate agents.

\section{Hypoxic pulmonary vasoconstriction}

Reports are now appearing about the use of nifedipine for the treatment of hypoxic pulmonary vasoconstriction (HPV) in association with chronic obstructive pulmonary disease (COPD). ${ }^{11,12}$ No long-term trials have been published, but acute treatment regimes with oral nifedipine seem to lead to decreased pulmonary artery pressure, especially in association with exercise ${ }^{12}$ leading to increased exercise ability. Kennedy et al. ${ }^{12}$ in their study showed that there was significant reduction in the $\mathrm{PaO}_{2}$ associated with the decrease in pulmonary vascular resistance index, presumably due to increased shunting. However, they point out that in most cases there was a significant increase in oxygen delivery because of decreased SVR and increased C.O. and no change in the mixed venous oxygen content despite the decrease in $\mathrm{PaO}_{2}$. Nifedipine may be a useful adjuvant to supplement oxygen in the treatment of hypoxic pulmonary hypertension.

With anaesthesia, two aspects should be considered. Firstly, certain circumstances exist when HPV works to our advantage, namely with one lung anaesthesia. Secondly, the reduction in $\mathrm{PaO}_{2}$ noted above may become more important under anaesthesia when the reflex increase in C.O. may not be present in order to increase oxygen delivery to the periphery and thus compensate for the lower $\mathrm{PO}_{2}$.

\section{Malignant hyperthermia ${ }^{50}$}

Because abnormal calcium transport plays an important role in the genesis of malignant hyperthermia, it has been postulated that calcium channel blockers could have a beneficial effect in its prevention or treatment.

Verapamil has been shown to prevent muscle contracture in vitro in human muscle susceptible to malignant hyperthermia in one report (cited in reference 50).

A study of eight China/Poland pigs ${ }^{50}$ was undertaken using a loading dose of $0.5 \mathrm{mg} \cdot \mathrm{kg}^{-1}$ of verapamil and a constant infusion of $0.035 \mathrm{mg}$. $\mathrm{kg}^{-1} \cdot \mathrm{min}^{-1}$ during halothane anaesthesia. The only effect that was seen in this study was that a delay in onset of the malignant hyperthermia process from one to five minutes in untreated animals to $25-30$ minutes in animals treated with calcium channel blockers. All the animals in the study eventually died. However, no treatment of the malignant hyperthermia was undertaken

It would appear that calcium channel blockers alone, are ineffective in the treatment of malignant hyperthermia. Further studies are required to determine whether or not these agents might be useful adjuncts in the treatment of the condition. However, as previously noted, untoward interactions with dantrolene may also preclude their use.

\section{Inhibition of platelet aggregation ${ }^{13}$}

Studies in vitro with human platelets have shown that both verapamil and nifedipine have effects on inhibiting platelet aggregation induced by various activators, such as epinephrine, collagen and adenosine diphosphate. ${ }^{13}$

Although the potential implication that calcium channel blockers could possibly interfere with 
coagulation perioperatively exists, there are no clinical reports to substantiate this possibility and it would appear that this is not an important problem.

\section{Hyperkalemia}

Several studies in animals found unexpected hyperkalemia following verapamil therapy. The first such study ${ }^{43}$ was in swine being studied for the interaction of verapamil and dantrolene. An incidental finding was a significant increase in serum potassium in animals receiving both drugs, in some instances up to two times the initial level of potassium.

In another study ${ }^{51}$ with dogs, the authors were concerned about the combined AV nodal conduction and myocardial depression of verapamil, halothane and hyperkalemia. Their model produced this combination and the effects were monitored. $\mathrm{KCl}$ was infused until the EKG showed signs of severe hyperkalemia. Haemodynamic measurements were obtained and the differences noted. Verapamil treated dogs required, on the average, one third the dose of $\mathrm{KCl}$ required to produce EKG changes and serum levels comparable to the control group $(\sim 9.0 \mathrm{mEq} / \mathrm{L})$. There was also an augmentation of the haemodynamic effects compared to those seen with hyperkalemia alone.

Although these studies were conducted in animals, and further study should be undertaken in man, the data suggest that verapamil-treated dogs require less potassium than nontreated animals to develop haemodynamic effects of acute hyperkalemia. Use of verapamil in renal failure patients could lead to a significant rise in serum potassium; however, further study is needed.

\section{Summary}

Clinical uses of calcium channel blockers are expanding. In addition to the established uses in patients with arrhythmias, angina pectoris or hypertension, newer and to some extent investigational uses indicate widespread application. For instance, their use has been reported in hypertrophic cardiomyopathy and cold cardioplegia, as well as in pulmonary hypertension, antiplatelet therapy, asthma, achalasia and oesophageal spasm, increased intraocular pressure and in cerebral vasospasm. Their use in obstetrical practice has been proposed.

Thus, the presentation of a patient who is treated with calcium channel blockers and who requires anaesthesia will become more common.

Calcium channel blockers may, under certain cirumstances, potentiate haemodynamic and MAC depressive effects of inhalation agents. There is also evidence that the effects of neuromuscular blocking agents may be potentiated. The anaesthetist should be aware that the potential for interactions exists with digoxin, propranolol, quinidine, theophylline or dantrolene.

Of interest and some significance are the anaesthetic implications of pathophysiological alterations that can be induced by calcium channel blockers, by affecting lower aesophageal tone, intracranial hypertension, bronchomotor tone (asthma), muscular dystrophy, neuromuscular function, hypoxic pulmonary vasoconstriction, malignant hyperthermia, inhibition of platelet aggre gation and hyperkalemia.

Despite these significant potential anaesthetic implications and because, at this time, in some instances withdrawal has clearly demonstrated increase in the signs of myocardial ischaemia, it would not seem necessary to recommend preoperative discontinuation of calcium channel blocker medication in patients presenting for anaesthesia. It is, however, appropriate that there is a high index of awareness of potential problems, unless there is some modification in inhalation anaesthetic concentrations and neuromuscular blocker dosage. Monitoring of cardiovascular and neuromuscular functions is essential.

Calcium channel blockers would appear to be currently the drugs of choice for angina pectoris, arrhythmias or hypertension in patients with associated chronic obstructive pulmonary disease.

\section{References}

1 Merin RG. Pharmacologic therapy in cardiac patients: calcium channel and beta-adrenergic blocking drugs. American Society of Anesthesiologists Refresher Course Lectures. 1984; 212.

2 Reaves JG, Kissin I, Lell WA, Tosone S. Calcium entry blockers: uses and implications for anesthesiologists. Anesthesiology 1983; 57; 504-18.

3 Merin RG. Slow channel inhibitors, anesthetics and cardiovascular function (Editorial). Anesthesiology 1981; 55: 198-200.

4 Opie LH. Calcium antagonists. Mechanisms, thera- 
peutic indications and reservations: a review. Quart J Med 1984; 209: 1-16.

5 Jones RM. Calcium antagonists (Editorial). Anaesthesia 1984; 39: 747-9.

6 Mizgala $H F$. The calcium channel blockers: pharmacology and clinical applications. Can Anaesth Soc J 1983; 30: S5:10.

7 Kraynack BJ. Calcium channel blocking agents: side effects and drug interactions. American Society of Anesthesiologists Refresher Course Lectures $1983 ; 238$.

8 Britt BA. Diltiazem: a review. Can Anaesth Soc J 1985; 32: 30-45.

9 Lee TH, DiSesa VJ, Cohn LH, Lilly LS, Antman $E M$. Correction of intraoperative diastolic myocardial dysfunction with nifedipine. Clin Cardiol 1983; 6: 549-52.

10 Hicks GL, Salley RK, DeWeese JA. Calcium channel blockers: an intraoperative and postoperative trial in women. Ann Thorac Surg 1984; 37: 319-23.

11 Simonneau G, Escourrou P, Duroux P, Lockhart $A$. Inhibition of hypoxic pulmonary vasoconstriction by nifedipine. N Engl J Med 1981; 304: 1582-5.

12 Kennedy TP, Michael JR, Huang CK et al. Nifedipine inhibits hypoxic pulmonary vasoconstriction during rest and exercise in patients with chronic obstructive pulmonary disease. Am Rev Respir Dis 1984; 129: 544-51

13 Han $P$, Boatwright C, Ardlie NG. Effect of the calcium-entry blocking agent nifedipine on activation of human platelets and comparison with verapamil. Thromb Haemostas 1983; 50: 513-7.

14 Svedmyr K, Lofdahl CG, Svedmyr N. Nifedipine - a calcium channel blocker - in asthmatic patients. Allergy 1984; 39: 17-22.

15 Patel KR. Calcium antagonists in exercise-induced asthma. Br Med J 1981; 282: 932-3.

16 Becker BS, Burakoff $R$. Effect of verapamil on the lower esophageal spincter pressure in normal subjects and in achalasia. Am J Gastroenterol 1983; 78: 773-5.

17 Bortolotti M, Labo G. Clinical and manometic effects of nifedipine in patients with esophageal achalasia. Am J Gastroenterol 1981; 80: 39-44.

18 Blackwell JN, Holt S, Heading RC. Effect of nifedipine on oesophageal motility and gastric emptying. Digestion 1981; 21: 50-6.

19 Monica ML, Hesse RJ, Messerli FH. The effect of a calcium channel blocking agent on intraocular pressure. Am J Ophthal 1983; 96: 814.

20 Pourrat JP and Douste-Blazy P. Renal side effect of nifedipine. Clin Cardiol 1984; 7: 29-30.

21 Schulte-Sasse $U$, Hess W, Markschies-Hornung A, Tarnow J. Combined effects of halothane anaesthesia and verapamil on systemic hemodynamics and left ventricular myocardial contractitlity in patients with ischemic heart disease. Anesth Analg 1984; 63: 7691-8.

22 Kapur PA, Flacke WE. Epinephrine-induced arrhythmias and cardiovascular function after verapamil during halothane anaesthesia in the dog. Anesthesiology 1981; 55: 218-25.

23 Lawson NW, Kraynack BJ, Gintautas J. Neuromuscular and electrocardiographic responses to verapamil in dogs. Anesth Analg 1983; 62: 50-4.

24 Kraynack BI, Lawson NW, Gintautas J. Neuromuscular blocking action of verapamil in cats. Can Anaesth Soc J 1983; 30: 242-7.

25 Kapur PA, Bloor BC, Flacke WE, Olewine SK. Comparison of cardiovascular responses to verapamil during enflurane, isoflurane or halothane anesthesia in the dog. Anesthesiology 1984; 61: $156-60$.

26 Maze $M$, Mason DM. Verapamil decreases the MAC for halothane in dogs. Anesth Analg 1983; 62: 274.

27 Bikhazi GB, Leung I, Foldes FF. Interaction of neuromuscular blocking agents with calcium channel blockers. Anesthesiology 1982; 57: A268.

28 Kraynack BJ, Lawson NW, Gintautas J, Tjay HT. Effects of verapamil on indirect muscle twitch responses. Anesth Analg 1983; 62: 827-30.

29 Durant NN, Nguyen N, Briscoe JR, Katz RL. Potentiation of pancuronium and succinylcholine by verapamil. Anesthesiology 1982; 57: A267.

30 Durani NN, Nguyen N, Katz RL. Potentiation of neuromuscular blockade by verapamil. Anesthesiology 1984; 60: 298-303.

31 Carpenter $R L$, Mulroy $M F$. Edrophonium antagonizes combined verapamil-pancuronium neuromuscular blockade. Anesthesiology 1983; 59: A272.

32 Zaiman F, Perloff $J K$, Durant NN, Campion DS. Acute respiratory failure following intravenous verapamil in Duchenne's muscular dystrophy. Am Heart J 1983; 105: 510-1.

33 van Poorten JF, Dhasmana KM, Kuypers RS, Erdmann $W$. Verapamil and reversal of vecuronium 
neuromuscular blockade. Anesth Analg 1984; 63:

155-7.

34 Pederson KE, Thayssen $P$, Klitgaard NA, Christian$\operatorname{sen} B D$. Nielsen-Kudsk $F$. Influence of verapamil on the inotropism and pharmacokinetics of digoxin. Eur J Clin Pharmacol 1983; 25: 199-206.

35 Lander $R$. Verapamil/beta-blocker interaction: a review. Missouri Med 1983; 80: 626-9.

36 Kieval J, Kirsten EB, Kessler KM, Mallon SM, Myerburg RJ. The effects of intravenous verapamil on hemodynamic status of patients with coronary artery disease receiving propanolol. Circulation 1982; 65: 653-9

37 Oesterle SN, Schroeder JS. Editorial: Calcium entry blockade, beta-adrenergic blockade and the reflex control of circulation. Circulation 1982; 65: 669-70.

38 Packer M, Meller J, Medina N et al. Hemodynamic consequences of combined beta-adrenergic and slow calcium channel blockade in man. Circulation 1982; 65: 660-8.

39 Leon MB, Rosing DR, Bonow RO, Lipson LC, Epstein SE. Clinical efficacy of verapamil alone and combined with Propranolol in treating patients with chronic stable angina pectoris. Am J Cardiol 1981; 48: 131-9.

40 Green JA, Clementi WA, Porter C. Stigelman W. Nifedipine-quinidine interaction. Clin Pharm 1983; 2: 461-5.

41 Burnakis TG, Seldon $M$, Czaplicki AD. Increased serum theophylline concentrations secondary to oral verapamil. Clin Pharm 1983; 2: 458-61.

42 Parrillo $S J$, Venditto $D O$. Elevated theophylline blood levels from institution of nifedipine therapy. Ann Emerg Med 1984; 13: 216-7.

43 Saltzman LS, Kates RA, Corke BC, Norfleet EA, Heath $K R$. Hyperkalemia and cardiovascular collapse after verapamil and dantrolene administration in swine. Anesth Analg 1984; 63: 473-8.

44 Durbin CG, Fisher NA, Lynch II C. Cardiovascular effects in dogs of intravenous dantrolene alone and in the presence of verapamil. Anesthesiology 1983; 59: A227.

45 Bedford RF, Dacey R, Winn HR, Lynch III C. Adverse impact of a calcium entry-blocker (verapamil) on intracranial pressure in patients with brain tumors. J Neurosurg 1983; 59: 800-2.

46 Giffin JP, Cottrell JE, Hartung J, Shwiry B. Intracranial pressure during nifedipine-induced hypotension. Anesth Analg 1983; 62: 1078-80.
47 Rogers MC, Hamburger C. Orven K, Epstein MH Intracranial presure in the cat during nitroglycerininduced hypotension. Anesthesiology 1979; 51: 227-9.

48 Marsh ML, Shapiro HM, Smith RW, Marshall LF. Changes in neurologic status and intracranial pressure associated with sodium nitroprusside administration. Anesthesiology 1979; 51: 336-8.

49 Williams DO, Barnes PJ, Vickers $H P$, Rudolf $M$ Effects of nifedipine on bronchomotor tone and histamine reactivity in asthma. Br Med $\mathrm{J} 1981$; 283-348.

50 Zukaitis MG, Hoech GP, Williams $C H$, Simpson $S$. Verapamil attenuation of the malignant hyperthermia syndrome in susceptible pigs. Anesthesiology 1982; 57: A228.

51 Nugent $M$, Tinker $J H$, Moyer TP. Verapamil worsens rate of development and hemodynamic effects of acute hyperkalemia in halothaneanesthetized dogs: effects of calcium therapy. Anesthesiology 1984; 60: 435-9. 